\title{
Falas do crime, segregação espacial e discriminação social
}

CALDEIRA, Teresa Pires do Rio.

Cidade de muros; crime, segregação

e cidadania em São Paulo

Trad. de Frank de Oliveira e Henrique Monteiro

São Paulo, Ed.34 / EDUSP, 2000

Resenhado por Yara Aun Khoury*

A CIDADE, COMO o "lugar em que se pode contemplar o mundo com a esperança de produzir um futuro", como nos sugere o professor Milton Santos (Santos, Folha de São Paulo, 2/2/01, E-14), é um campo fértil de estudo, quando nos dispomos a refletir sobre os processos por meio dos quais se forja nossa própria história. O traçado urbano, suas edificações, seu território, enfim, como o espaço apropriado, produzido e significado por seus habitantes, a cidade nos permite escutar, observar e procurar entender melhor os caminhos da mudança social e o nosso lugar nela. Uma avaliação cuidadosa, comprometida com as cidades contemporâneas, poderá nos revelar modos e expressões da constante expansão e reformulação do capitalismo, que tem na globalização sua versão mais atual, engendrando novas formas de concentração do poder, de segregação, de marginalização e de exclusão sociais.

O livro Cidade de Muros, de Teresa Caldeira, recentemente publicado, representa uma proveitosa contribuição nesse sentido. Particularmente interessada nas experiências de violência e no universo do crime como

* Professora do Departamento de História da PUC-SP e Coordenadora do CEDIC I PUC-SP. 
um contexto fértil (mas não o único) para o estudo da segregação espacial e da discriminação social na cidade, procura mostrar como, nesse universo, se entretecem de maneira imbricada dois novos modos de discriminação nas cidades modernas: a privatização da segurança e a reclusão de alguns grupos sociais em enclaves fortificados, articulados à formulação e circulação de estereótipos.

Este livro é sobre São Paulo, cidade onde a autora cresceu e passou a maior parte de sua vida. Mas, como ela mesma diz, seu estudo é marcado por suas experiências como moradora desta e de outras cidades, como Los Angeles, La Jolla e Nova York, por seus percursos nelas e, especialmente, pelos conflitos e tensões vividos na confluência dessas diversas experiências e pelos conhecimentos que elas geram.

Levantando e analisando, na singularidade de São Paulo, relações entre experiências e interpretações de violência, espaço público urbano e segregação espacial, seu "objetivo é entender e criticar processos mais amplos de transformação social e segregação que São Paulo exemplifica”.

Buscando compreender e explicar a complexidade e diversidade dessas experiências na cidade em suas imbricadas relações, elege três tipos de bairros. Visando compreender como a violência e a segregação são vividas e interpretadas numa zona de expansão da periferia, centra-se no bairro Jardim das Camélias, no distrito de São Miguel Paulista, ao mesmo tempo em que observa outros bairros em condições semelhantes. Enfoca problemas que moldam o cotidiano de seus moradores, preocupações que expressam em relação ao crime, como se organizam em movimentos. Em outra direção, destaca a Moóca, como bairro de classe média baixa, hoje desindustrializado e em processo de remodelação, por nela se expressarem processos novos e contraditórios. Nesse bairro, muitas casas, grandes e antigas, transformam-se em cortiços, convivendo com áreas que vão sendo reurbanizadas e enobrecidas graças à construção da linha de metrô. Estende também sua pesquisa para o Morumbi e Alto de Pinheiros, bairros de classes mais altas, onde se expressa de maneira mais clara o novo padrão de segregação espacial da cidade: os condomínios fechados, elementos fortes na proliferação da segurança privada.

Explorando fontes de natureza variada e privilegiando o trabalho com entrevistas, observa as interpretações que os sujeitos fazem da violência, do crime e das instituições e práticas que os alimentam e/ou 
controlam. Analisa modos como discursos, instituições e práticas da violência projetam-se no espaço urbano e com ele se articulam, engendrando, no seu dizer, novas estratégias de proteção e reação, estabelecendo diferenças, impondo divisões e distâncias, construindo separações, multiplicando regras de evitação e exclusão e restringindo os movimentos. Vê na construção de muros na cidade uma das expressões materiais mais emblemáticas dessas estratégias.

Caminhando entre falas, práticas e instituições e analisando-as pelo viés da violência e da segregação na cidade, a autora leva-nos a refletir sobre a vida nas regiões urbanas e a identificar nelas questões que se constituem em obstáculos à construção de relações mais democráticas, não só em São Paulo, como em outras cidades e países.

O livro está organizado em quatro partes articuladas entre si. $\mathrm{Na}$ primeira, em meio a uma observação das transformações políticas, sociais e econômicas vividas no Brasil, entre os anos 1980 e 90, analisa "as estruturas de narrativas de crimes e a maneira pela qual elas, simbolicamente, reorganizam o mundo desestruturado por experiências de crime".

$\mathrm{Na}$ segunda, usando entrevistas e apoiando-se em estatísticas de crime e na história das forças policiais, trata do crime e das instituições da ordem, procurando entender o crime violento. Destaca a responsabilidade dessas forças na reprodução da violência, associada a uma descrença generalizada na justiça e à adoção de medidas violentas e privadas de segurança pela população.

$\mathrm{Na}$ terceira, indicadores demográficos e socio-econômicos, anúncios e notícias de jornais subsidiam o estudo da emergência de um novo estilo de condomínios habitacionais fechados entre as formas pelas quais as transformações urbanas combinam-se ao crime, ao medo da violência e ao desrespeito ao direito da cidadania. Fazendo comparações com Los Angeles, vai tornando visível como, por meio de muros se produz e se expressa um novo tipo de espaço público urbano, marcado pela desigualdade, pela separação e pelo controle de fronteiras. Daí a simbologia impregnada no título de sua obra: Cidade de Muros...

$\mathrm{Na}$ quarta parte, focalizando o que considera uma ligação intrínseca entre violência, desrespeito aos direitos civis e tolerância em relação a manipulações do corpo, vigente no Brasil, mostra como esses fenômenos, intimamente imbricados, continuam a se reproduzir, articulados a um processo de desligitimação da justiça. 
Entre as muitas contribuições que apresenta para nossa reflexão sobre processos de segregação que se expressam nos contornos e no traçado da cidade e com eles se articulam, chama nossa atenção a análise que faz do que nomeia "fala do crime". Privilegiando-a como um rico elemento para a compreensão da heterogeneidade e das tensões sociais engendradas nesses processos de violência e de transformação urbana, nas falas de diferentes moradores da cidade sobre o crime, sejam eles simples trabalhadores, membros de classes mais abastadas, administradores públicos, políticos, membros de grupos de direitos humanos, vai recuperando dimensões da realidade urbana paulistana.

Suas explicações sobre os sentidos e os significados dessa fala na realidade vivida pelos moradores de São Paulo, e na sua própria investigação, já se iniciam pelo reconhecimento dos limites que se impõem a uma pesquisa sobre experiências de violência e de segregação e pela observação das significativas diferenças nas reações de moradores de bairros de periferia e de classe média e alta, quando indagados sobre este assunto, alvo de tantos temores.

Ouvindo múltiplas e contraditórias vozes, leva-nos a refletir sobre modos como "a fala do crime" contribui na reordenação simbólica do mundo elaborando preconceitos e naturalizando a percepção de certos grupos como perigosos, a ponto de esses próprios grupos internalizarem essa fala. Dá-nos mostras evidentes da criminalização simbólica como um processo social dominante, atuando de maneira incisiva na construção de práticas e espaços sociais, tanto na sua dimensão física quanto imaginária.

O modo como trabalha discursos e estratégias de proteção entretecendo-se com transformações no próprio espaço e no viver urbanos, engendrando novos padrões de vida, novas concepções de espaço público, de desligitimação da justiça e de direitos civis, tem se mostrado uma abordagem inovadora e proveitosa para refletirmos sobre processos históricos como experiência vivida.

Para além de explorar a fala como elemento significativo na construção de uma realidade social, ao longo de sua obra, Caldeira chama nossa atenção pela maneira comprometida com que reflete, como profissional e como cidadã, sobre o universo da violência e sobre a cidade. Um comentário, na introdução ao seu livro, é bastante sugestivo nesse sentido. Referindo-se à sua experiência de escrevê-lo em inglês e não 
em sua língua materna, o português, convida-nos a refletir sobre os significados da língua e da cultura na construção histórica.

Imbuída de uma concepção de língua como um elemento constitutivo da cultura dentro da qual cada pessoa cresce, se forma, molda formas de pensamento e reflete, expressa o conflito vivido nessa experiência, particularmente no que diz respeito às diferentes perspectivas e estilos acadêmicos entre Brasil e Estados Unidos e até mesmo em relação à sua tradução para o português, feita por terceiros. Destacando que o papel do intelectual nos Estados Unidos está freqüentemente dissociado de uma função pública e de uma reflexão como cidadão preocupado com problemas de sua sociedade, reafirma seu empenho em conservar a intenção crítica em seu trabalho, uma das características da noção brasileira do papel público dos intelectuais.

Melhor do que qualquer comentário, suas próprias palavras dizem muito mais:

"Quando escrevo sobre São Paulo, em português, para brasileiros, escrevo como intelectual e como cidadã, e, portanto, abordo a cidade de uma certa maneira. Cidades das quais somos cidadãos são cidades nas quais queremos intervir, que queremos construir, reformar, criticar e transformar. Elas não podem ser deixadas intocadas, implícitas, ignoradas. Manter intocado o imaginário de sua própria cidade é incompatível com um estudo (ou um projeto) de transformação social. Cidades que permanecem cristalizadas em imagens passadas que temos medo de tocar não são cidades que habitamos como cidadãos, mas cidades de nostalgia, cidades com que sonhamos. As cidades (sociedades, culturas) em que vivemos estão, como nós mesmos, mudando continuamente. Elas são cidades para serem refletidas, questionadas, mudadas. São cidades com as quais nos envolvemos."

Considerando o movimento constante da realidade social e investindo em reflexões sobre as implicações da língua e da fala na construção e transformação dessa realidade, essa obra convida-nos a investir em estudos que explorem possibilidades de intervenção, por meio da reflexão sobre o potencial da língua falada como uma prática social e como uma das expressões da cultura. 